\title{
Potential Impact of the COVID-19 Pandemic on Financial Toxicity in Cancer Survivors
}

\author{
Khalil Baddour et al. ${ }^{1}$ \\ ${ }^{1}$ Affiliation not available
}

April 28, 2020

\begin{abstract}
Background: In the context of COVID-19, cancer survivors represent a particularly vulnerable population that may be "doubly hit" both by costs of cancer treatment and financial strain imposed by the pandemic.

Methods: We performed a review of the literature pertaining to cancer, financial toxicity, and economic challenges.

Results: Multiple societies have put forth recommendations to modify delivery of cancer care in order to minimize patient exposure to the virus. Cancer survivors, especially patients with head and neck cancer, have been disproportionately affected by rising unemployment levels and economic recessions in the past, both of which are linked to higher cancer mortality. Patients who rely on employer-provided insurance and do not qualify for Medicaid may lose access to life-saving treatments.

Conclusions: It is essential to implement interventions and policy changes in order to mitigate the effects of this pandemic but also to ensure this becomes a non-issue during the next one.
\end{abstract}

\section{Introduction}

Financial toxicity is defined as the objective and subjective patient-level impact of the costs of cancer care and can afflict even those with health insurance. ${ }^{1}$ It is linked to decreased health-related quality of life (HRQOL), and increased symptom burden, emotional distress, and mortality. ${ }^{2-8}$ In the context of coronavirus disease 2019 (COVID-19), cancer survivors (defined as such from the time of diagnosis) represent a particularly vulnerable population that may be disproportionately affected by financial burdens surrounding the pandemic. Cancer survivors already spend more out-of-pocket (OOP) for medical care than patients with other chronic illnesses. ${ }^{9}$ This is a pervasive pattern that persists many years after diagnosis and completion of treatment. ${ }^{8,9}$

Since December 2019, the pandemic has spread rapidly ${ }^{10,11}$ propagating economic disruption globally and, in many cases, overwhelming healthcare resources. ${ }^{12}$ Necessary physical distancing measures have been established around the world to attenuate the propagation of the virus, resulting in significant consequences for most businesses and workers. ${ }^{13,14,15}$ Patients with cancer may take a "double hit" from both costs of cancer care and financial strains imposed by the pandemic related to 1) prolonged unemployment for both cancer survivors and their caregivers; 2) the possibility of additional disease burden from treatment delay or interruptions; and 3) increased risk of COVID-19 infection (and its resulting health consequences). As such, cancer survivors require particular consideration as we consider the financial consequences and related subjective distress surrounding COVID-19.

\section{Impact of COVID-19 Infection on Cancer Care Delivery}

Early reports from China observed that patients with cancer harbored a higher risk of infection compared with the overall population ${ }^{16}$ and that oncologic patients have an elevated risk of admission to the intensive care unit, invasive ventilation, and death. ${ }^{17}$ Nonetheless, these remain preliminary reports with small, heterogeneous samples. While data on immunosuppressed patients remain limited, the potential threat for 
immunocompromised cancer survivors is not to be ignored. Head and neck cancer (HNC) survivors, who already incur some of the highest cancer-related treatment $\operatorname{costs}^{18}$, may represent a population particularly vulnerable to viral transmission. On account of the diseases they treat, otolaryngologists and, by extension, their patients are at a higher risk of contracting the virus. ${ }^{19}$ To this effect, otolaryngology clinics and departments around the world have altered their regular workflow and practice. ${ }^{20,21}$ The American Academy of Otolaryngology - Head and Neck Surgery (AAOHNS) and the American Head and Neck Society (AHNS), among others, have put forth recommendations that include limiting elective procedures, transferring nonurgent visits to remote care via telemedicine, and implementing strict aerosol precautions and appropriate personal protective equipment (PPE) donning for emergent procedures. ${ }^{22-24}$ For patients with malignancies, oncology providers must weigh the risks of viral exposure with that of treatment delay and potentially disease progression, both of which, if not well-balanced, may lead to exacerbated financial toxicity and poorer health outcomes. Interventions to emulate may be modeled after centers which have faced similar situations during previous coronavirus epidemics including 1) developing a multi-pronged approach; 2) focusing on a crisis management plan; and 3) transparency in leadership and communication regarding specific recommendations for both inpatient and outpatient oncologic patients, staff management, infection control, and recovery after control of the outbreak. ${ }^{25}$

It is imperative to note, however, that this does not make a case against physical distancing as models show that short-term business closures are necessary to mitigate a potentially worse long-term economic collapse that may result from additional lives lost without strong containment measures. ${ }^{26}$ The pandemic is predicted to have significant impacts on the economy beyond the immediate effects of public health measures. A recent article analyzing historic data from the 1918 influenza pandemic in the United States concluded that the pandemic lead to a sharp and persistent decline in economic activity, reducing manufacturing output by $18 \% .{ }^{27}$ Reports studying prior economic recessions have also found a link between such economic decline and mortality. ${ }^{28,29}$ Research by health economists has identified heterogeneity in the effect of recessions on mortality. While the relationship between macroeconomic environments and health behaviors has remained generally stable, cancer mortality has become more sensitive to financial strain and limited access to health resources when compared to other diseases. ${ }^{30}$ This phenomenon is postulated to result from advances in expensive cancer treatments and technologies, which places cancer survivors at a particular disadvantage during difficult economic climates.

\section{Impact of COVID-19 Economic Repercussions on Cancer Survivors}

In late March, a record 6.6 million people filed for unemployment in the United States, while some models anticipate the unemployment rate to rise up to $32 \%$ for the second quarter of $2020 .{ }^{31,32}$ Cancer survivors that will be affected by this may be at a higher risk for financial burden than the general population and more severe financial toxicity than would normally be expected. ${ }^{33,34}$ Indeed it is predicted that low-wage and self-employed workers will face the greatest risk of immediate financial burdens. ${ }^{35}$ Cancer survivors with low income at baseline, loss of wages, or perceived social isolation already face higher levels of financial toxicity than their counterparts. ${ }^{33,34}$ These are all factors that may be exacerbated by necessary public health measures such as physical distancing. Thus low-earning or socially isolated cancer survivors may represent some of the highest risk groups for increased financial toxicity during the pandemic compared to the general population and other cancer survivors.

Survivors employed in services that cannot be offered from home may be disproportionately affected and forced into temporary unemployment. Unpublished data from an ongoing prospective study examining financial toxicity in HNC survivors at our institution suggests that this may constitute up to $61.6 \%$ (45/73) of patients with squamous cell carcinoma (SCC) of the upper aerodigestive system. In a previous cross-sectional investigation of insured patients who completed primary treatment for SCC of the oral cavity, oropharynx, or larynx/hypopharynx, we found differences in financial toxicity by primary site, with worst financial toxicity in larynx/hypopharynx patients. This finding illuminates potential site-specific factors, e.g. workplace discrimination or inability to return to work, that may contribute to increased risk. ${ }^{36}$ Of all working-age cancer survivors ( $45 \%$ of people diagnosed with cancer) ${ }^{37}$ just $54 \%$ report working full time. ${ }^{38}$ This number 
will certainly be affected in the short-term, but these effects may linger long after acute pandemic control measures have been lifted. An increased proportion of cancer survivors may potentially suffer long-term cancer-associated job loss as a result of economic repercussions on the job market; a potentially less supportive and accommodating work environment; ${ }^{39}$ decreased functional status; ${ }^{40}$ and loss of productivity which cancer survivors already experience at greater levels than patients without a cancer history. ${ }^{41}$

Employment provides sense of self-fulfillment and return to normalcy, social interaction, financial compensation, as well as critical health care benefits. Despite changes under the Affordable Care Act (ACA), employer-sponsored health insurance coverage remains the dominant source of insurance in the US with close to half of all those covered in the US receiving insurance from an employer. ${ }^{42}$ Long-term cancer survivors report higher rates of "job lock," i.e. a perceived need to stay at a specific job to maintain health insurance, compared with similar workers with no cancer history ${ }^{43,44}$ Low-income workers who lose their jobs in the wake of the pandemic may have few coverage options depending on where they live. As of early 2020, 14 states had not expanded their Medicaid programs as allowed by the ACA, and many low-income adults in these states fall into a "coverage gap" given they do not qualify for Medicaid but their incomes are too low to qualify for subsidized private insurance. ${ }^{45}$ The prevalence of financial toxicity is not limited to low-income individuals, though. In previously published work from our group, we found that among Medicare and private beneficiaries, groups conventionally perceived as well-insured and less likely to face many of the socioeconomic barriers encountered by traditional Medicaid patients, financial toxicity remains a major concern. ${ }^{36}$ Middle-income cancer survivors who previously qualified for employer-provided insurance and do not qualify for Medicaid may be gravely affected by the ongoing unemployment crisis. While the ACA created insurance Marketplaces to provide private coverage options, most of these plans have highdeductibles, and middle-income patients may not be able to afford required premiums and cost-sharing. ${ }^{46-48}$ With loss of employment and their employment health benefits, they may be "priced out" and face a bleak choice between less than optimal treatment and financial ruin. This echoes predictions from 2008 noting that "at least 25,000 patients with cancer undergoing treatment in 2009 [would] lose coverage as a result of the recession" ${ }^{49}$ A preliminary report estimates that 1.55 million newly unemployed persons will lose health insurance coverage due to the pandemic. ${ }^{50}$ The study does not stratify this estimate per disease, but it is safe to say that cancer survivors will certainly be among those affected.

Multiple studies have suggested that cancer-related financial strain may be linked to decreased self-reported HRQOL, thereby contributing to a greater mortality risk..$^{2,3,5-8}$ This is at least in part attributable to maladaptive coping strategies such as treatment non-adherence. ${ }^{51}$ In attempts to remedy increasing costs, patients limit use of medications, miss clinical appointments, borrow money, take credit card loans or have

family members work additional hours. ${ }^{51-54}$ One study found a link between the 2008 economic recession and a decreased rate of cancer treatment, ${ }^{55}$ implying that during economic hardships, patients may be less likely to seek cancer care due to financial constraints. Moreover, attainment of basic necessities may be disproportionately affected in cancer survivors who have reported greater levels of food insecurity (worrying about whether food would run out, food spoiling, and the inability to afford balanced meals) compared to individuals without a cancer history. ${ }^{56}$ These coping strategies may be amplified during the COVID-19 pandemic with the potential for devastating consequences on health and health outcomes, including cancer progression and death. A longitudinal analysis of data from 75 countries has in fact demonstrated that sharp unemployment rises such as that from 2008 to 2010 were significantly associated with an increase in all-cancer mortality and all specific cancers except lung cancer in women. ${ }^{57}$ The study further estimated an excess of about 260,000 cancer-related deaths associated with the 2008 to 2010 economic crisis. ${ }^{57}$ History informs us that we must examine these issues urgently as we grapple with the economic repercussions and resulting health consequences on cancer survivors.

\section{Impact of the Pandemic on Cancer Survivors' Mental Health}

Economic hardship and its ramifications may also significantly effect patients' mental health. ${ }^{58}$ Unemployment has been reported to be strongly associated with suicide [odds ratio (OR) 2.6, $95 \%$ confidence interval (CI) 2.0-3.4]. ${ }^{59}$ In a study investigating "economic suicides", it was found that the 2008 recession was as- 
sociated with at least 10,000 additional suicides in Europe and North America between 2008 and 2010. ${ }^{60}$ The effect of the COVID-19 pandemic on mental health and suicide rates is difficult to predict. Several large-scale studies have linked a current cancer diagnosis with increased incidence of suicide (from a 1.9-fold risk $^{61}$ to a 4.4 -fold risk ${ }^{62}$ in a more recent study) when compared to the general population. HNC survivors, in particular, have been found to be at higher risk of suicide and suicide-related death compared to patients with other types of cancer. ${ }^{62,63}$ Cancer-related financial toxicity has been associated with depressed mood (OR 1.95, 95\% CI 1.29-2.95), ${ }^{5}$ all of which may be exacerbated by unemployment and economic burden during this pandemic. This highlights an imperative need for the incorporation of mental health services and supportive interventions, even if these services may only be delivered through telehealth platforms within the current framework of public health measures.

\section{Discussion and Future Directions}

Calls have been made to reduce survivor exposure to the virus by postponing adjuvant treatments or elective surgeries for "stable patients" ${ }^{17}$ and minimizing extended treatments whenever possible. ${ }^{64}$ These measures may not only limit exposure but also decrease potentially unnecessary treatment-related financial toxicity at this critical time. Additionally, there is a critical need - now more than ever before - to promote financial planning among patients and improve the frequency and content of patient-provider communication concerning expected OOP expenses ${ }^{65}$ It is essential to adopt an approach of shared decision-making, involving patients not only in conversations regarding goals of care, but also discussions involving access to care, availability of caregiver support, and exposures to financial toxicity. This also raises the need for early palliative care intervention and incorporation within treatment plans. Although the capacity for palliative care may be limited at this time due to increased demand ${ }^{66}$ experiences from other institutions do provide a framework to improve delivery of high-quality palliative care during the pandemic. ${ }^{67,68}$ These measures, however, do not specifically address patients with cancer, as of yet. The potential vulnerability of this patient population, both to the infection itself as well as the economic ripples of the pandemic, highlight an urgent need for future paradigms specifically addressing cancer survivors.

The pandemic and its economic repercussions have the potential to disproportionately affect cancer survivors' financial status and, as a result, their HRQOL and mortality. ${ }^{2-8}$ Estimation of financial toxicity is a complex problem. The socioeconomic impacts due to COVID-19 are multi-layered and include 1) loss of household income due to unemployment and death of earning members; 2) temporary or permanent closure of small businesses; and 3) loss of productivity of a business. We have a variety of questions to address in order to fully examine these issues. For example, how should we conduct optimal survey designs for such studies? What are the suitable variables to investigate? How do we model these resulting data? Studies such as these may have a major impact on healthcare delivery systems, payors, providers, and consumers.

We may start to tackle these questions by heightening our sensitivity - developing a collective consciousness - to the increased vulnerability of our patients to financial toxicity in the context of the COVID-19 pandemic. There is a need to develop interventions and facilitate policy changes at local and national levels to mitigate the effects of the current pandemic as well as protect our patients from cyclic infectious outbreaks and recurrent recessions. Though telemedicine is a tool, it is not the solution. Despite the recent unprecedented adoption of such technology to manage patients remotely, the current health crisis has revealed widespread discrepancies in telehealth systems and regulations surrounding reimbursement. We must get creative and leverage multidisciplinary stakeholders, not only within tertiary practice centers, but also within our communities to balance the virtualization of care delivery with critical in-person visits. By doing so, we may strive to minimize treatment interruptions and non-adherence and help our patients attenuate the adverse outcomes of financial toxicity during and after the COVID-19 era.

\section{Full author list}

Khalil Baddour, MD Department of Otolaryngology - Head and Neck Surgery, University of Pittsburgh School of Medicine, Pittsburgh, PA 
Lauren D. Kudrick, MA, Med Department of Medicine, Division of Infectious Diseases; Department of Otolaryngology - Head and Neck Surgery, University of Pittsburgh School of Medicine, Pittsburgh, PA

Aakriti Neopaney Department of Otolaryngology - Head and Neck Surgery, University of Pittsburgh School of Medicine, Pittsburgh, PA

Lindsay M. Sabik, PhD Department of Health Policy and Management, University of Pittsburgh Graduate School of Public Health; University of Pittsburgh Health Policy Institute; UPMC Hillman Cancer Center; Pittsburgh, PA

Shyamal D. Peddada, PhD Department of Biostatistics, University of Pittsburgh Graduate School of Public Health, Pittsburgh, PA

Marci L. Nilsen, PhD, RN Department of Acute and Tertiary Care, University of Pittsburgh School of Nursing; Department of Otolaryngology - Head and Neck Surgery, University of Pittsburgh School of Medicine, Pittsburgh, PA

Jonas T. Johnson, MD Department of Otolaryngology - Head and Neck Surgery, University of Pittsburgh School of Medicine, Pittsburgh, PA

Robert L. Ferris, MD, PhD UPMC Hillman Cancer Center; Department of Otolaryngology - Head and Neck Surgery, University of Pittsburgh School of Medicine, Pittsburgh, PA

Leila J. Mady, MD, PhD, MPH Department of Otolaryngology - Head and Neck Surgery, University of Pittsburgh School of Medicine, Pittsburgh, PA

Keywords: Coronavirus; COVID-19; Cancer; Financial Toxicity; Head and Neck

Disclosure Statement: The authors have no conflicts of interest to declare.

Acknowledgments: The authors would like to thank Aishat Okunade for her help and contributions to this article.

Funding: This work was supported by American Academy of Otolaryngology - Head \& Neck Surgery Foundation (AAO-HNSF) and the Centralized Otolaryngology Research Effort (CORE) Study Section Health Services Research Grant (Mady, Johnson); and UPMC Hillman Cancer Center Specialized Programs of Research Excellence (Ferris, Mady)

\section{References}

1. Zafar SY, Peppercorn JM, Schrag D, et al. The financial toxicity of cancer treatment: a pilot study assessing out-of-pocket expenses and the insured cancer patient's experience. The oncologist.2013;18(4):381.

2. Carrera PM, Kantarjian HM, Blinder VS. The financial burden and distress of patients with cancer: understanding and stepping-up action on the financial toxicity of cancer treatment. CA: a cancer journal for clinicians. 2018;68(2):153-165.

3. Fenn KM, Evans SB, McCorkle R, et al. Impact of financial burden of cancer on survivors' quality of life. Journal of oncology practice. 2014;10(5):332-338.

4. Huang I-C, Bhakta N, Brinkman TM, et al. Determinants and consequences of financial hardship among adult survivors of childhood cancer: a report from the St. Jude Lifetime Cohort Study. JNCI: Journal of the National Cancer Institute. 2019;111(2):189-200. 
5. Kale HP, Carroll NV. Self-reported financial burden of cancer care and its effect on physical and mental health-related quality of life among US cancer survivors. Cancer. 2016;122(8):283-289.

6. Lathan CS, Cronin A, Tucker-Seeley R, Zafar SY, Ayanian JZ, Schrag D. Association of financial strain with symptom burden and quality of life for patients with lung or colorectal cancer. Journal of Clinical Oncology. 2016;34(15):1732.

7. Ramsey SD, Bansal A, Fedorenko CR, et al. Financial insolvency as a risk factor for early mortality among patients with cancer. Journal of Clinical Oncology. 2016;34(9):980.

8. Zafar SY, McNeil RB, Thomas CM, Lathan CS, Ayanian JZ, Provenzale D. Population-based assessment of cancer survivors' financial burden and quality of life: a prospective cohort study. Journal of oncology practice. 2015;11(2):145-150.

9. Guy Jr GP, Ekwueme DU, Yabroff KR, et al. Economic burden of cancer survivorship among adults in the United States. Journal of Clinical Oncology. 2013;31(30):3749.

10. Holshue ML, DeBolt C, Lindquist S, et al. First Case of 2019 Novel Coronavirus in the United States. New England Journal of Medicine. 2020;382(10):929-936.

11. Wu Z, McGoogan JM. Characteristics of and Important Lessons From the Coronavirus Disease 2019 (COVID-19) Outbreak in China: Summary of a Report of 72314 Cases From the Chinese Center for Disease Control and Prevention. JAMA. 2020.

12. Grasselli G, Pesenti A, Cecconi M. Critical Care Utilization for the COVID-19 Outbreak in Lombardy, Italy: Early Experience and Forecast During an Emergency Response. JAMA. 2020.

13. Anderson RM, Heesterbeek H, Klinkenberg D, Hollingsworth TD. How will country-based mitigation measures influence the course of the COVID-19 epidemic? The Lancet. 2020;395(10228):931-934.

14. Hafiz H, Oei S-Y, Ring DM, Shnitser N. Regulating in Pandemic: Evaluating Economic and Financial Policy Responses to the Coronavirus Crisis. Boston College Law School Legal Studies Research Paper.2020(527).

15. Brenan M. U.S. Employees Increasingly Seeing COVID-19 Effects at Work. Gallup. 2020. https://news.gallup.com/poll/3 increasingly-seeing-covid-effects-work.aspx. . Accessed March 31, 2020.

16. Yu J, Ouyang W, Chua MLK, Xie C. SARS-CoV-2 Transmission in Patients With Cancer at a Tertiary Care Hospital in Wuhan, China. JAMA Oncology. 2020.

17. Liang W, Guan W, Chen R, et al. Cancer patients in SARS-CoV-2 infection: a nationwide analysis in China. The Lancet Oncology.2020;21(3):335-337.

18. Jacobson JJ, Epstein JB, Eichmiller FC, et al. The cost burden of oral, oral pharyngeal, and salivary gland cancers in three groups: commercial insurance, Medicare, and Medicaid. Head Neck Oncol.2012;4:15.

19. Position Statement: Otolaryngologists and the COVID-19 Pandemic.American Academy of OtolaryngologyHead and Neck Surgery 2020; https://www.entnet.org/content/otolaryngologists-and-covid-19-pandemic. Accessed April 1, 2020.

20. Chan JYK, Wong EWY, Lam W. Practical Aspects of Otolaryngologic Clinical Services During the 2019 Novel Coronavirus Epidemic: An Experience in Hong Kong. JAMA Otolaryngology-Head $\&$ Neck Surgery. 2020 .

21. Saibene AM, Allevi F, Biglioli F, Felisati G. Role and management of a head and neck department during the COVID-19 Outbreak in Lombardy. Otolaryngology - Head and Neck Surgery. 2020.

22. Information for Head and Neck Oncologists During the COVID-19 Pandemic (from the Survivorship, Supportive Care \& Rehabilitation Service). 2020; https://www.ahns.info/wp-content/uploads/2020/03/synthesizedphysician-doc.pdf. Accessed April 4, 2020. 
23. Academy Supports CMS, Offers Specific Nasal Policy. 2020; https://www.entnet.org/content/academysupports-cms-offers-specific-nasal-policy. Accessed April 4, 2020.

24. Ueda M, Martins R, Hendrie PC, et al. Managing cancer care during the COVID-19 pandemic: Agility and collaboration toward a common goal. Journal of the National Comprehensive Cancer Network.2020;1(aop):14 .

25. Jazieh A-R, Hadab AA, Olayan AA, et al. Managing Oncology Services During a Major Coronavirus Outbreak: Lessons From the Saudi Arabia Experience. JCO Global Oncology. 2020(6):518-524.

26. Cornwall W. Can you put a price on COVID-19 options? Experts weigh lives versus economics. In. Science 2020.

27. Correia S, Luck S, Verner E. Pandemics Depress the Economy, Public Health Interventions Do Not: Evidence from the 1918 Flu. SSRN.2020;Pre-print.

28. Hone T, Mirelman AJ, Rasella D, et al. Effect of economic recession and impact of health and social protection expenditures on adult mortality: a longitudinal analysis of 5565 Brazilian municipalities.Lancet Glob Health. 2019;7(11):e1575-e1583.

29. Sullivan D, von Wachter T. Job Displacement and Mortality: An Analysis Using Administrative Data*. The Quarterly Journal of Economics. 2009;124(3):1265-1306.

30. Ruhm CJ. Recessions, healthy no more? Journal of Health Economics. 2015;42:17-28.

31. Cox J. Coronavirus job losses could total 47 million, unemployment rate may hit $32 \%$, Fed estimates. CNBC. 2020. https://www.cnbc.com/2020/03/30/coronavirus-job-losses-could-total-47-million-unemploymentrate-of-32percent-fed-says.html. Accessed April 1, 2020.

32. Unemployment Insurance Weekly Claims Report April 2, 2020. In: Labor USDo, ed2020.

33. Gordon LG, Merollini KMD, Lowe A, Chan RJ. A Systematic Review of Financial Toxicity Among Cancer Survivors: We Can't Pay the Co-Pay.Patient. 2017;10(3):295-309.

34. de Souza JA, Kung S, O'Connor J, Yap BJ. Determinants of Patient-Centered Financial Stress in Patients With Locally Advanced Head and Neck Cancer. J Oncol Pract. 2017;13(4):e310-e318.

35. Casselman B, Cohen P, Cowley S, et al. Coronavirus Cost to Businesses and Workers: 'It Has All Gone to Hell'. The New York Times. March 15, 2020, 2020.

36. Mady LJ, Lyu L, Owoc MS, et al. Understanding financial toxicity in head and neck cancer survivors. Oral Oncol. 2019;95:187-193.

37. Howlader N, Noone A, Krapcho M, et al. SEER Cancer Statistics Review, 1975-2016. Bethesda, MD: National Cancer Institute. In:2019.

38. Banegas MP, Guy Jr GP, de Moor JS, et al. For working-age cancer survivors, medical debt and bankruptcy create financial hardships. Health Affairs. 2016;35(1):54-61.

39. Mehnert A. Employment and work-related issues in cancer survivors. Critical reviews in oncology/hematology. 2011;77(2):109-130.

40. Steiner JF, Cavender TA, Main DS, Bradley CJ. Assessing the impact of cancer on work outcomes. Cancer. 2004;101(8):1703-1711.

41. Ekwueme DU, Yabroff KR, Guy Jr GP, et al. Medical costs and productivity losses of cancer survivorsUnited States, 2008-2011.MMWR Morbidity and mortality weekly report. 2014;63(23):505.

42. Health Insurance Coverage of the Total Population. 2018; https://www.kff.org/other/state-indicator/totalpopulation/?currentTimeframe=0\&sortModel=\%7B $\% 22$ colId $\% 22: \% 22$ Location $\% 22, \% 22$ sort $\% 22: \% 22$ asc $\% 22 \% 7 D$. Accessed April 8, 2020. 
43. Kirchhoff AC, Nipp R, Warner EL, et al. "Job lock" among long-term survivors of childhood cancer: a report from the Childhood Cancer Survivor Study. JAMA oncology. 2018;4(5):707-711.

44. Blinder VS, Gany FM. Impact of Cancer on Employment. Journal of clinical oncology: official journal of the American Society of Clinical Oncology. 2020;38(4):302.

45. Garfield R, Orgera K, Damico A. The Coverage Gap: Uninsured Poor Adults in States that Do Not Expand Medicaid. January 2020. Accessed April 8, 2020.

46. Cost-Sharing for Plans Offered in the Federal Msrketplace, 2014-2020. December 9, 2019; https://www.kff.org/slideshow/c sharing-for-plans-offered-in-the-federal-marketplace-2014-2020/. Accessed April 8, 2020.

47. Fehr R, Kamal R, Cox C. How ACA Marketplace Premiums Are Changing by County in 2020. November 7, 2019; https://www.kff.org/health-costs/issue-brief/how-aca-marketplace-premiums-are-changing-bycounty-in-2020/. Accessed April 8, 2020.

48. Pollitz K. What People (and Policymakers) Can Do About Losing Coverage During the COVID-19 Crisis. March 27, 2020; https://www.kff.org/coronavirus-policy-watch/what-people-and-policymakers-cando-about-losing-coverage-during-the-covid-19-crisis/. Accessed April 8, 2020.

49. Senior K. Battling cancer and the recession. Lancet Oncol.2009;10(3):212-213.

50. Woolhandler S, Himmelstein DU. Intersecting U.S. Epidemics: COVID-19 and Lack of Health Insurance. Annals of Internal Medicine. 2020.

51. Kaisaeng N, Harpe SE, Carroll NV. Out-of-pocket costs and oral cancer medication discontinuation in the elderly. Journal of Managed Care Pharmacy. 2014;20(7):669-675.

52. de Souza JA, Kung S, O'Connor J, Yap BJ. Determinants of patient-centered financial stress in patients with locally advanced head and neck cancer. Journal of oncology practice.2017;13(4):e310-e318.

53. Costas-Muniz R, Leng J, Aragones A, et al. Association of socioeconomic and practical unmet needs with self-reported nonadherence to cancer treatment appointments in low-income Latino and Black cancer patients. Ethnicity $\&$ health. 2016;21(2):118-128.

54. Streeter SB, Schwartzberg L, Husain N, Johnsrud M. Patient and plan characteristics affecting abandonment of oral oncolytic prescriptions. Journal of oncology practice. 2011;7(3S):46s-51s.

55. Ennis KY, Chen M-H, Smith GC, et al. The Impact of Economic Recession on the Incidence and Treatment of Cancer. J Cancer.2015;6(8):727-733.

56. Zheng Z, Jemal A, Tucker-Seeley R, et al. Worry About Daily Financial Needs and Food Insecurity Among Cancer Survivors in the United States. 2020;18(3):315.

57. Maruthappu M, Watkins J, Noor AM, et al. Economic downturns, universal health coverage, and cancer mortality in high-income and middle-income countries, 1990-2010: a longitudinal analysis.Lancet. 2016;388(10045):684-695.

58. Jahoda M. Economic recession and mental health: Some conceptual issues. Journal of social Issues. 1988;44(4):13-23.

59. Lewis G, Sloggett A. Suicide, deprivation, and unemployment: record linkage study. BMJ. 1998;317(7168):12831286.

60. Reeves A, McKee M, Stuckler D. Economic suicides in the Great Recession in Europe and North America. British Journal of Psychiatry. 2014;205(3):246-247.

61. Misono S, Weiss NS, Fann JR, Redman M, Yueh B. Incidence of suicide in persons with cancer. Journal of clinical oncology : official journal of the American Society of Clinical Oncology.2008;26(29):4731-4738. 
62. Zaorsky NG, Zhang Y, Tuanquin L, Bluethmann SM, Park HS, Chinchilli VM. Suicide among cancer patients. Nat Commun. 2019;10(1):207.

63. Osazuwa-Peters N, Simpson MC, Zhao L, et al. Suicide risk among cancer survivors: Head and neck versus other cancers. Cancer.2018;124(20):4072-4079.

64. Katz MS. Cancer Care in the Time of COVID-19. 2020; https://connection.asco.org/blogs/cancer-caretime-covid-19?cid=DM4800\&bid=40974521. Accessed March 31, 2020.

65. Yabroff KR, Bradley C, Shih Y-CT. Understanding financial hardship among cancer survivors in the United States: Strategies for prevention and mitigation. Journal of Clinical Oncology. 2019:JCO. 19.01564.

66. Powell VD, Silveira MJ. What Should Palliative Care's Response be to the COVID-19 Epidemic? Journal of Pain and Symptom Management.

67. Fausto J, Hirano L, Lam D, et al. Creating a Palliative Care Inpatient Response Plan for COVID19 The UW Medicine Experience.J Pain Symptom Manage. 2020.

68. Calton B, Abedini N, Fratkin M. Telemedicine in the Time of Coronavirus. J Pain Symptom Manage. 2020 . 